\title{
RHODANESE ACTIVITY: A SIMPLE AND RELIABLE TAXONOMIC TOOL FOR GRAM-NEGATIVE BACTERIA
}

\section{B. LÁNYI}

\section{National Institute of Hygiene, POB 64, H-1966, Budapest, Hungary}

\begin{abstract}
Summary. The thiosulphate:cyanide sulphurtransferase (rhodanese) test of Vandenbergh, Bawdon and Berk (1979) has been simplified and 2469 strains from a wide variety of sources representing different biochemical, serological or phage-pattern entities were tested. The percentages of rhodanese-producing strains were: Escherichia coli $98 \%$, Shigella flexneri serovars $1-5 \%$, X and Y $0 \%$, other shigellae $73-100 \%$, Yersinia spp. $0 \%$, Salmonella subgenera I-IV $0 \%$, Citrobacter freundi $16 \%$, Klebsiella 37\%, Enterobacter 4\%, Hafnia alvei $61 \%$, Proteus spp. $0 \%$, Pseudomonas spp. $98-100 \%$. Rhodanese production by $S$. flexneri serovar 6 supports the view that this group of bacteria should be removed from $S$. flexneri and placed in another species of Shigella.
\end{abstract}

\section{INTRODUCTION}

Rhodanese (thiosulphate: cyanide sulphurtransferase, E.C.2.8.1.1) is a constitutive intracellular enzyme that catalyses the formation of thiocyanate from cyanide and thiosulphate. It was demonstrated in photosynthetic bacteria (Yoch and Lindstrom, 1971) and in Pseudomonas aeruginosa (Schook and Berk, 1978). A practical test for the detection of rhodanese in bacteria has been developed by Vandenbergh et al. (1979), who screened the lysozyme-lysed cells of 411 strains belonging mainly to the family Enterobacteriaeceae.

The present paper gives an account of rhodanese activity in 2469 bacterial strains tested by a simplified procedure.

\section{MATERIALS AND METHODS}

Organisms. Reference strains from the Hungarian National Collection of Medical Bacteria, Budapest (Lányi and Konkoly Thege, 1978) and fresh isolates were used (see table). The cultures represented different biochemical, serological or phage-pattern entities and were isolated from a wide variety of sources.

Test procedure. A modification of the method of Vandenbergh et al. (1979) was used and the bacteria were grown for $20 \mathrm{~h}$ at $37^{\circ} \mathrm{C}$ on nutrient agar containing $5 \%(\mathrm{v} / \mathrm{v})$ ox blood, except that some pseudomonads were incubated at $30^{\circ} \mathrm{C}$ for optimum growth.

A fresh solution of lysozyme (Reanal, Budapest) $5 \mathrm{mg} / \mathrm{ml}$ in water was made at 2-day intervals and stored at $4{ }^{\circ} \mathrm{C}$. Equal parts of the lysozyme solution and a $20 \mathrm{~mm}$ stock solution of disodium ethylenediaminetetraacetate (EDTA) were mixed each day and distributed as $0.5-\mathrm{ml}$ portions in $100 \times 10 \mathrm{~mm}$ tubes. Several loopfuls of growth from the blood agar were transferred to the lysozyme-EDTA mixture to make a heavy suspension corresponding visually to a standard containing c. $3 \times 10^{10}$ cells $/ \mathrm{ml}$. The maximum number of strains tested in one experiment was 60 . The tubes were incubated at $25^{\circ} \mathrm{C}$ for $60 \mathrm{~min}$.

The substrate mixture was prepared each day from stock solutions of $0 \cdot 125 \mathrm{M}$ sodium thiosulphate ( 2 volumes), $0.1 \mathrm{M}$ Tris adjusted to $p \mathrm{H} 8.0$ ( 1 volume), and $0.25 \mathrm{M}$ potassium cyanide (1 volume). The potassium cyanide stock solution was stored at $4^{\circ} \mathrm{C}$ for not longer than 1 week. The substrate mixture $(0.5 \mathrm{ml})$ was added to the lysozyme-treated bacteria by means of a Cornwall dispenser. The mixtures were shaken, incubated in a waterbath at $37^{\circ} \mathrm{C}$ for $15 \mathrm{~min}$, and shaken again. 
The reagent for the detection of thiocyanate was freshly prepared from 4 volumes of $0.1 \mathrm{M}$ ferric nitrate in $13 \%$ nitric acid and 1 volume of $38 \%(\mathrm{v} / \mathrm{v})$ formaldehyde and $0.5 \mathrm{ml}$ was added to each tube. The tubes were inspected immediately and a positive reaction was indicated by an instantaneous, distinct, slowly-fading brownish-red colour varying in strength with individual strains. Weakly positive reactions were indicated by a pale orange colour and reactions considered negative by honey yellow or faint yellow.

Procedures in which KCN was handled were performed in a cabinet equipped with exhaust ventilation. The tubes and flasks containing the remainder of the $\mathrm{KCN}$ reagent were discarded by immersing them in potassium permanganate solution (c. $15 \mathrm{~g}$ in $3 \mathrm{~L}$ of tap water).

\section{RESULTS}

\section{Reproducibility of the rhodanese test}

Distinct positive and negative tests were always reproducible. Negative tests, characterised by a honey-yellow colour, were less constant and the strength of the yellow colour varied. Thus the differentiation between these and weak-positive reactions needed some practice.

The suspension of many strains, mainly of Pseudomonas, Klebsiella and S. sonnei, became slimy and to give an evenly distributed colour reaction, the suspensions needed vigorous shaking.

The number of bacteria suspended in the lysozyme-EDTA mixture was critical and in the range $10^{11}-5 \times 10^{9}$ cells $/ \mathrm{ml}$ rhodanese production was readily detectable. The positive reactions became fainter at lower counts and below $10^{9} / \mathrm{ml}$ there was a tendency towards weakly positive or even negative tests.

The duration of the lyzozyme-EDTA treatment was not critical but the colour reaction was sensitive to the amount of EDTA in the system; at concentrations higher than the optimum, the brownish-red colour quickly faded or even failed to appear.

There was no spontaneous production of thiocyanate; if rhodanese-producing bacteria were boiled before testing, the colour of the test was pale yellow.

Vandenbergh et al. (1979) regarded as negative an absorbance of $<0.1$ at $460 \mathrm{~nm}$. To establish that our visual readings were valid, supernates obtained by centrifugation after completing the reaction by the procedure described here were read in a Spekol (Carl Zeiss, GDR) spectrophotometer at $460 \mathrm{~nm}$. Positive and negative tests differed significantly in absorbance values and there was a smaller but measurable difference between the pale-yellow and honey-yellow negative reactions. The honey-yellow colour is probably associated with a minor degree of thiocyanate formation but, in practice, it is more feasible to regard the honey-yellow colour as negative because it is difficult to distinguish from the pale-yellow colour of a "true-negative" reaction.

\section{Distribution of rhodanese activity}

The table shows that the presence or absence of rhodanese activity was a characteristic of the majority of isolates within a given taxon. Exceptions were Shigella, Citrobacter, Klebsiella and Hafnia, among which some strains were positive and some negative.

Among the strains of Shigella, rhodanese activity was distributed according to definite subentities of the genus. $S$. flexneri strains, except $S$. flexneri serovar 6 , were uniformly negative. The rest of shigellae were positive, and only some old laboratory strains of $S$. boydi serovars 3 and 11 , and $S$. dysenteriae serovars 3, 5, 8 and 10 failed to produce rhodanese.

Rhodanese production was characteristic of E. coli, except for one fresh isolate (serogroup $\mathrm{O} 25)$, and seven laboratory strains: O17: $\mathrm{K} 16: \mathrm{H} 18, \quad \mathrm{O} 23: \mathrm{K} 18: \mathrm{H} 15, \quad \mathrm{O} 56: \mathrm{K}^{\circ}: \mathrm{H}^{-}$, $\mathrm{O} 96: \mathrm{K} \cdot: \mathrm{H} 19, \mathrm{O} 158: \mathrm{K} \cdot: \mathrm{H} 20$ (one strain of each) and $\mathrm{O} 138: \mathrm{K} 81: \mathrm{H} 14$ (two strains). E. coli strains with $\mathrm{O}$ antigens identical with, or related to, S. flexneri antigens were uniformly rhodanese-positive.

In the genus Pseudomonas, most strains were strongly positive. Thus 94 strains of unclassified fluorescent pseudomonads (Ajello and Hoadley, 1976; Lányi, Hoadley and Ajello, 1979), one strain each of $P$. aminovorans, $P$. aureofaciens, $P$. cepacia, $P$. maltophilia, $P$. 
TABLE

Results of a modified rhodanese test on 2469 strains of gram-negative bacteria

\begin{tabular}{|c|c|c|c|c|c|c|c|}
\hline \multirow[b]{3}{*}{ Genus } & \multirow{3}{*}{$\begin{array}{l}\text { Species or } \\
\text { subgenus }\end{array}$} & \multirow{3}{*}{$\begin{array}{l}\text { Number } \\
\text { of strains } \\
\text { tested }\end{array}$} & \multicolumn{4}{|c|}{$\begin{array}{l}\text { Number of strains } \\
\text { that were rhodanese }\end{array}$} & \multirow{3}{*}{$\begin{array}{l}\text { Percentage } \\
\text { positive }\end{array}$} \\
\hline & & & \multicolumn{2}{|c|}{ positive } & \multicolumn{2}{|c|}{ negative } & \\
\hline & & & + & $(+)$ & $(-)$ & - & \\
\hline Escherichia & coli $^{*}$ & 426 & 418 & 0 & 3 & 5 & 98 \\
\hline \multirow[t]{5}{*}{ Shigella } & boydi & 33 & 31 & 0 & 0 & 2 & 94 \\
\hline & dysenteriae & 30 & 22 & 0 & 2 & 6 & 73 \\
\hline & fiexneri serovar 6 & 19 & 19 & 0 & 0 & 0 & 100 \\
\hline & flexneri other & 86 & 0 & 0 & 0 & 86 & 0 \\
\hline & sonnei & 94 & 94 & 0 & 0 & 0 & 100 \\
\hline \multirow[t]{2}{*}{ Yersinia } & enterocolitica & 153 & 0 & 0 & 0 & 153 & 0 \\
\hline & pseudotuberculosis & 21 & 0 & 0 & 0 & 21 & 0 \\
\hline \multirow[t]{4}{*}{ Salmonella } & subgenus I & 254 & 0 & 0 & 157 & 97 & 0 \\
\hline & subgenus II & 15 & 0 & 0 & 1 & 14 & 0 \\
\hline & subgenus III & 64 & 0 & 0 & 32 & 32 & 0 \\
\hline & subgenus IV & l & 0 & 0 & 0 & 1 & 0 \\
\hline Citrobacter & freundi & 85 & 12 & 2 & 35 & 36 & 16 \\
\hline Edwardsiella & tarda & 1 & 0 & 0 & 1 & 0 & 0 \\
\hline Klebsiella & various & 119 & 22 & 22 & 23 & 52 & 37 \\
\hline Enterobacter & various & 54 & 0 & 2 & 36 & 16 & 4 \\
\hline Serratia & marcescens & 3 & 0 & 0 & 0 & 3 & 0 \\
\hline Hafnia & alvei & 51 & 12 & 19 & 14 & 6 & 61 \\
\hline \multirow[t]{5}{*}{ Proteus } & vulgaris & 100 & 0 & 0 & 0 & 100 & 0 \\
\hline & mirabilis & 100 & 0 & 0 & 0 & 100 & 0 \\
\hline & morgani & 156 & 0 & 0 & 0 & 156 & 0 \\
\hline & rettgeri & 42 & 0 & 0 & 0 & 42 & 0 \\
\hline & inconstans & 82 & 0 & 0 & 0 & 82 & 0 \\
\hline \multirow[t]{4}{*}{ Pseudomonas } & aeruginosa & 262 & 261 & 1 & 0 & 0 & 100 \\
\hline & fluorescens & 40 & 40 & 0 & 0 & 0 & 100 \\
\hline & UFPt & 94 & 92 & 2 & 0 & 0 & 100 \\
\hline & othert & 84 & 79 & 3 & 0 & 2 & 98 \\
\hline
\end{tabular}

$+=$ Reaction colour brownish-red; $(+)$ pale orange; $(-)$ honey yellow; - pale yellow.

* Includes eight anaerogenic strains ("Alkalescens-dispar").

+ Unclassified fluorescent pseudomonads - see text.

\pm See text.

Percentages in italics derived from $<20$ strains.

pseudomallei, $P$. putrefaciens, $P$. stutzeri, $P$. syringae and $P$. testosteroni, 22 strains of unidentified fluorescent an 51 strains of unidentified non-fluorescent pseudomonads were positive. In contrast, $P$. alcaligenes, strain NCTC10367 and $P$. diminuta, strain NCTC8545, failed to produce detectable amounts of rhodanese.

Subtle differences in the "negative" reaction were also of some value. Thus all strains tested of S. flexneri (except serovar 6), Yersinia spp. and Proteus spp. gave a pale-yellow colour, whereas some strains of Citrobacter, Klebsiella and Enterobacter and the majority of strains of Salmonella gave a honey-yellow colour.

\section{DISCUSSION}

Vandenbergh et al. (1979) detected rhodanese activity in E. coli (132 strains), Shigella (37 strains), Citrobacter (10 strains), Acinetobacter (24 strains) and P. aeruginosa (30 strains), but not in Salmonella (21 strains), Klebsiella (92 strains) and Proteus (44 strains).

We have devised a simplified test, and by the use of smaller test volumes, higher concentrations of bacteria and some reagents, and visual instead of photometric reading, we have obtained reproducible results that agree in the most part with those of Vandenbergh et al. (1979). Exceptions among S. flexneri, C. freundi and Klebsiella may be attributed to the testing 
of a greater variety of strains in the present study. Whether or not rhodanese-positive and rhodanese-negative Klebsiella strains belong to defined subentities of the genus, remains to be investigated.

From the results of Vandenbergh et al. (1979) and of the present study, it may be suggested that rhodanese production is an important factor in the characterisation of higher taxons of the Enterobacteriaceae and other gram-negative bacteria. The test may be useful to distinguish between anaerogenic E. coli and $S$. flexneri, between Salmonella and rhodanese-positive Citrobacter or between rhodanese-producing Klebsiella and other Enterobacteriaceae.

The difference in rhodanese production between S. flexneri serovar 6 and other S. flexneri strains is especially interesting. On the basis of biochemical and genetic properties, it has been suggested (see Petrovskaya and Bondarenko, 1977) that S. flexneri 6 should be removed from the species $S$. flexneri and considered as one of the serovars of $S$. boydi. Rhodanese activity, which seems to be constant in $S$. flexneri 6, is a new character supporting this view.

I am grateful to Mrs M. Beck for skilled technical assistance.

\section{REFERENCES}

Ajello, G. W. AND Hoadley, A. W. 1976. Fluorescent pseudomonads capable of growth at $41^{\circ} \mathrm{C}$ but distinct from Pseudomonas aeruginosa. J. clin. Microbiol., 4, 443.

LÁNYi, B., HoAdley, A. W. AND AJELlo, G. W. 1979. Heat-stable somatic antigens of a group of unclassified fluorescent pseudomonads (UFP). Acta microbiol. hung., 26, 111.

LÁNyi, B. AND Konkoly Thege, M. 1978. Hungarian National Collection of Medical Bacteria, Catalogue 1978. National Institute of Hygiene, Budapest.

Petrovskaya, V. G. and Bondarenko, V. M. 1977. Recommended corrections to the classification of Shigella flexneri on a genetic basis. Int. J. syst. Bact., 27, 171.

SCHOOK, L. B. AND Berk, R. S. 1978. Nutritional studies with Pseudomonas aeruginosa grown on inorganic sulfur sources. J. Bact., 133, 1377.

VANDENBERGH, P. A., BAwDON, R. E. AND BeRK, R. S. 1979. Rapid test for determining the intracellular rhodanese activity of various bacteria. Int. J. syst. Bact., 29, 339.

Yoch, D. C. AND LiNDSTROM, E. S. 1971. Survey of the photosynthetic bacteria for rhodanese (thiosulfate: cyanide sulfur transferase) activity. J. Bact., 106, 700. 